https://helda.helsinki.fi

Early life origin of type 1 diabetes

\title{
Knip, Mikael
}

2017-11

Knip , M , Luopajarvi , K \& Harkonen , T 2017 , ' Early life origin of type 1 diabetes ' , Seminars in Immunopathology , vol. 39 , no. 6 , pp. 653-667 . https://doi.org/10.1007/s00281-017-0665-6

http://hdl.handle.net/10138/298164

https://doi.org/10.1007/s00281-017-0665-6

publishedVersion

Downloaded from Helda, University of Helsinki institutional repository.

This is an electronic reprint of the original article.

This reprint may differ from the original in pagination and typographic detail.

Please cite the original version. 


\title{
Early life origin of type 1 diabetes
}

\author{
Mikael Knip ${ }^{1,2,3,4} \mathbb{D} \cdot$ Kristiina Luopajärvi $^{1,2}$ • Taina Härkönen ${ }^{1,2}$
}

Received: 12 June 2017 / Accepted: 8 November 2017 / Published online: 23 November 2017

(C) Springer-Verlag GmbH Germany, part of Springer Nature 2017

\begin{abstract}
Type 1 diabetes (T1D) is perceived as a chronic immune-mediated disease with a subclinical prodromal period characterized by selective loss of insulin-producing beta cells in the pancreatic islets in genetically susceptible subjects. The incidence of T1D has increased manifold in most developed countries after World War II in parallel with a series of other immunemediated diseases. T1D results from gene-environmental interactions. The appearance of disease-associated autoantibodies into the peripheral circulation is the first detectable sign of the initiation of the disease process leading to clinical T1D. The first autoantibodies may appear already before the age of 6 months and the seroconversion rate peaks during the second year of life. This implies that exogenous factors involved in the pathogenesis of T1D must be operative in early life, some of them most likely already during pregnancy. Here, we discuss putative endogenous factors that may contribute to the development of T1D during fetal and early postnatal life. Many environmental factors operative in early life have been implicated in the pathogenesis of T1D, but relatively few have been firmly confirmed.
\end{abstract}

This article is a contribution to the special issue on Immunocompetence of the Newborn - Guest Editors: Arnaud Marchant and Tobias Kollmann

Mikael Knip

mikael.knip@helsinki.fi

1 Children's Hospital, University of Helsinki and Helsinki University Hospital, P.O. Box 22, (Stenbäckinkatu 11), FI

-00014 Helsinki, Finland

2 Research Programs Unit, Diabetes and Obesity, University of Helsinki, P.O. Box 22, (Stenbäckinkatu 11), FI -00014 Helsinki, Finland

3 Folkhälsan Research Center, Helsinki, Finland

4 Tampere Center for Child Health Research, Tampere University Hospital, Tampere, Finland
Keywords Type 1 diabetes · Environmental determinants · Conception · Fetal life $\cdot$ Postnatal life $\cdot$ Omics

\section{Natural history of type 1 diabetes}

An asymptomatic period of conspicuously variable duration precedes the clinical manifestation of type 1 diabetes (T1D) [1]. Aggressive beta cell destruction may result in disease presentation within a few months in infants and young children, while in other individuals, the process may continue for more than 20 years before the eventual manifestation of overt disease [2]. The appearance of diabetes-associated autoantibodies is the first detectable sign of emerging islet autoimmunity. There are five disease-related autoantibodies that have been shown to predict clinical T1D [3]. These include classical islet cell antibodies (ICA) detected by conventional immunofluorescence, insulin autoantibodies (IAA), and autoantibodies to the $65 \mathrm{kDa}$ isoform of GAD (GADA), the insulinoma-associated antigen (IA-2A), and zinc transporter 8 (ZnT8A). The latter four biochemical autoantibodies are usually analyzed with specific radiobinding assays. The number of detectable autoantibodies is unequivocally related to the risk of progression to clinical T1D both in family studies and in surveys based on general population cohorts.

The role of multiple autoantibodies in the prediction of T1D was analyzed in a combined series from the Finnish Diabetes Prediction and Prevention (DIPP) study, the German BABYDIAB study, and the American DAISY (Diabetes AutoImmunity Study in the Young) [4]. In the total series of 13,377 at-risk children, 585 (4.4\%) seroconverted to positivity for multiple autoantibodies. The life-table analysis showed that approximately $44 \%$ of those children progressed to overt T1D over the next 5 years, while that proportion increased to $70 \%$ by 10 years and to $84 \%$ after 15 years of 
follow-up. There were no significant differences in the progression rate between the three countries (Fig. 1) or between those with a family member affected by T1D and those with no family history. The following four factors predicted independently progression to clinical disease: (i) young age at seroconversion $(<3$ years), (ii) the high-risk HLA genotype (DR3/DR4-DQ8), (iii) female gender, and (iv) higher number $(\geq 3)$ of autoantibodies.

From the DIPP study recruiting newborn infants carrying HLA-conferred susceptibility to T1D (either the high-risk HLA genotype or moderate-risk HLA genotypes), we have learned that the first autoantibody may appear very early, even before the age of 6 months in a few infants [5]. IAA often emerges as the first autoantibody among very young children. The cumulative incidence of IAA was $2.9 \%$ by the age of 2 years and that of ICA $2.7 \%$, while GADA had a cumulative incidence of $1.6 \%$ and IA-2A $1.1 \%$. By the age of 5 years, $6.7 \%$ had ICA in at least two consecutive samples, whereas the corresponding proportion for IAA positivity was $5.0 \%$, for GADA 3.4\%, and for IA-2A 2.7\% in the DIPP study [6]. By the median age of 9.2 years, 1173 children out of 7410 followed (15.8\%) had ICA, 128 (1.9\%) tested positive had two autoantibodies, $87(1.2 \%)$ three autoantibodies, and $80(1.1 \%)$ tested positive for all four autoantibodies [7]. The age at seroconversion to IAA or GADA positivity among those, who developed multiple $(\geq 2)$ autoantibodies and in whom it was possible to define which antibody appeared first is presented in Fig. 2. This demonstrates that IAA show a sharp peak during the second year of life whereas GADA have a substantially lower and broader peak starting from the age of 2 and stretching up to the age of 5 years [8].

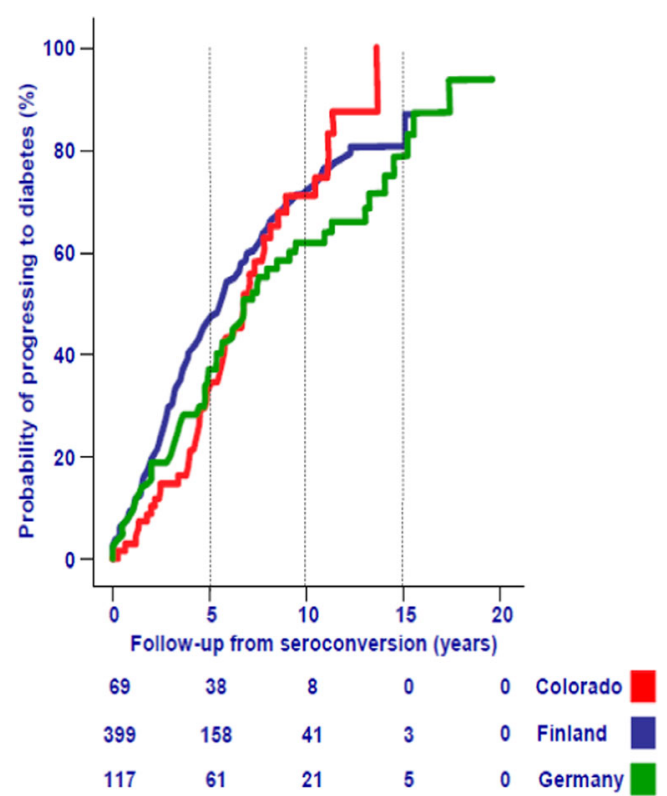

Fig. 1 Progression to type 1 diabetes from the time of seroconversion to autoantibody positivity in children with multiple $(\geq 2)$ diabetes-associated autoantibodies from three countries. Figure modified from [4]
Depending on the study design and sampling interval of prospective studies, the first emerging autoantibody can be identified in $60-80 \%$ of the children $[8,9]$. The emergence of IAA as the first detectable autoantibodies is associated with the HLA $D R 4-D Q 8$ haplotype and rapid progression to T1D, while the emergence of GADA as the first autoantibody is linked to the HLA $D R 3-D Q 2$ haplotype and a slower progression to overt disease. IA-2A and ZnT8A are rarely the first autoantibodies to emerge. These observations suggest that there are at least two different T1D phenotypes, which most likely are triggered by different environmental factors. This implies as well that there may be a need to apply different interventions in these two phenotypes.

\section{The role of environmental factors in type 1 diabetes}

There are a series of arguments in favor of a critical role of non-genetic factors in the development of T1D. These include both environmental and host-related factors. Studies in monozygotic twins indicate that only $13-33 \%$ are pairwise concordant for T1D [10,11], suggesting that there is either acquired postconceptional genetic discordance or differential exposure to the putative exogenous factor(s). The geographic variation in the T1D incidence in children is conspicuous even among Caucasians, with the lowest annual rate in Europe reported from Macedonia amounting to $5.8 / 100,000$ children under the age of 15 years in the time period 2004-2008 [12] and the highest rate observed in Finland reaching 65 in 2006 [13]. This more than 10fold difference in incidence can hardly be explained by genetic factors. A conspicuous increase in the incidence of T1D among children has been documented over the last

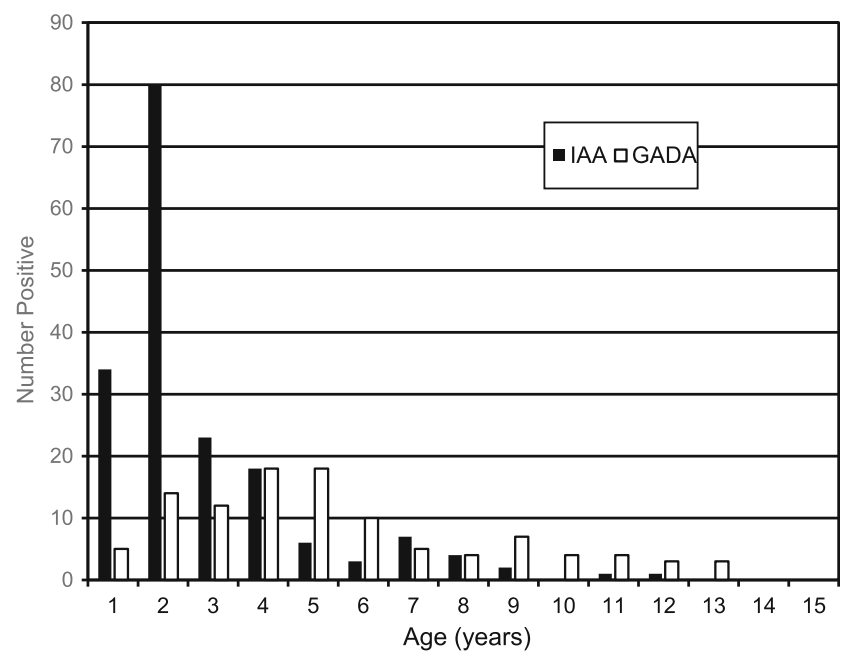

Fig. 2 Age of seroconversion to IAA and GADA among those participants in the Finnish Type 1 Diabetes Prediction and Prevention (DIPP) study, who have developed multiple $(\geq 2)$ autoantibodies and in whom the first appearing autoantibody can be defined 
decades, particularly in Europe-for example, in Finland, the incidence has increased 5.4-fold from the early 1950s [13]. Such an increase cannot be exclusively due to enhanced genetic disease susceptibility in the background population but must mostly be due to changes in lifestyle and environment. Migrant studies have been used to a limited extent in epidemiological surveys of T1D. However, available data imply that the rate of T1D has increased in population groups who have moved from a low-incidence region to a high-incidence area, stressing the influence of environmental conditions [14]. We observed that the prevalence of T1D was of the same magnitude among Somali children living in the Helsinki area as in native Finnish children [15], whereas T1D is rare in Somalia. Accumulating evidence indicates that the proportion of subjects with high-risk HLA genotypes has declined over the last decades among patients with newly diagnosed T1D, while the proportion of people with low-risk or even protective HLA genotypes has increased [16, 17]. These data are compatible with an increased environmental load leading to progression to clinical diabetes with less genetic susceptibility.

Next, we will discuss factors operative at conception and during pregnancy as well as early postnatal factors putatively involved in the development of T1D. Figure 3 lists some of the risk and protective factors related to their timing.

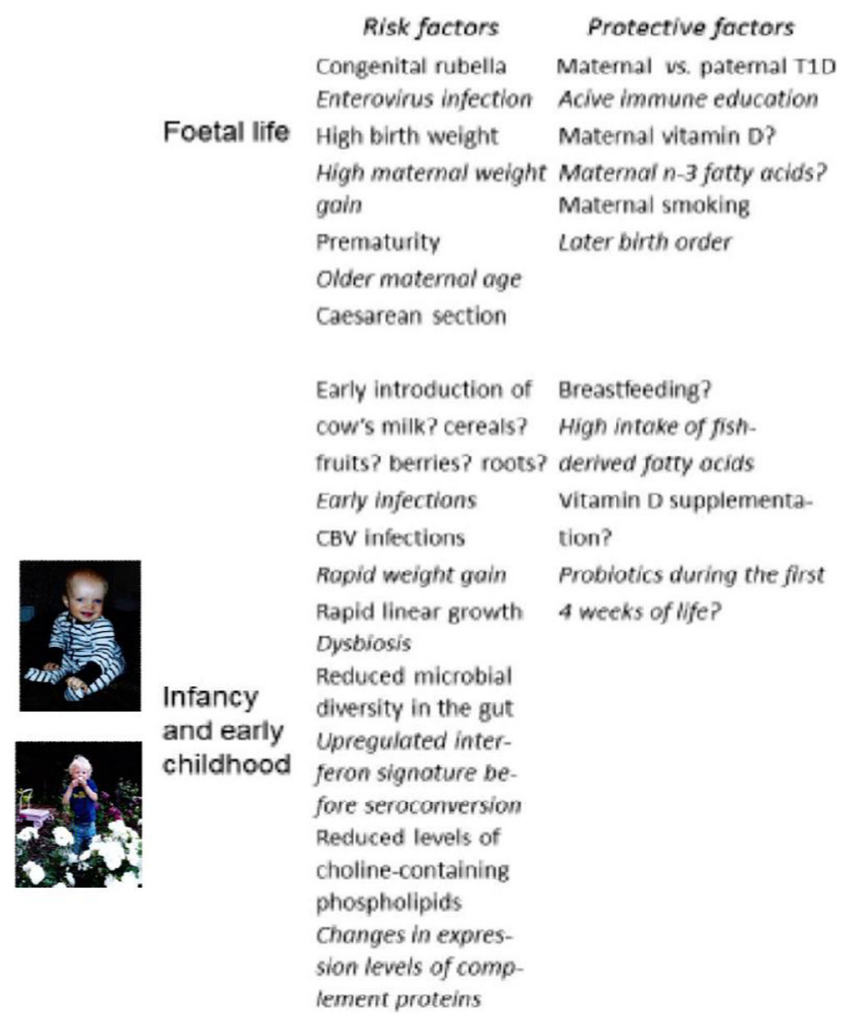

Fig. 3 Exogenous factors in early life implicated as risk or protective determinants of type 1 diabetes

\section{Factors operating at conception}

Maternal and paternal genes affect the risk of the offspring to progress to T1D. The most important genes contributing to T1D susceptibility are located in the HLA-DQ locus on the short arm of chromosome 6 [18]. Individuals carrying the HLA $D R 4-D Q 8$ or $D R 3-D Q 2$ haplotypes, or both are at increased risk of T1D [19] while those subjects who have inherited the HLA DR15-DQ6 haplotype from both of their parents are strongly protected from T1D. HLA genes have been estimated to explain approximately half of the genetic disease predisposition while the other half is due to more than 50 nonHLA genetic polymorphisms [19]. However, only a relatively small proportion of genetically susceptible individuals progress to overt disease. Genes inherited from the parents may operate in utero and/or postnatally. Genetic polymorphisms in, e.g., the INS locus are perceived to affect the expression of the insulin gene in the fetal thymus and thereby the selection of insulin reactive T cells and subsequent development of T1D [20].

Little is known about the impact of epigenetic modifications in the pathogenesis of T1D. The fertilized egg contains in addition to genes inherited from the mother and the father maternal cytoplasm and mitochondria, mRNA, proteins, nutrients, and other molecules, which may influence DNA methylation patterns and other epigenetic changes transmitting information into postnatal life. The levels of unmethylated insulin DNA in serum have been shown to be inversely correlated with decreased insulin secretion in individuals en route to T1D [21].

\section{Fetal and perinatal life}

\section{Parental T1D}

Offspring of T1D mothers have a 2-3-fold lower risk of progression to T1D than offspring of affected fathers [22, 23]. The reasons behind this surprising difference in risk have remained open. We have observed that infants of mothers affected by T1D have a higher proportion of regulatory $\mathrm{T}$ cells in their cord blood than infants of unaffected mothers and that the regulatory $\mathrm{T}$ cells from infants with maternal T1D are upregulated in vitro by insulin [24]. This observation indicates that maternal insulin treatment induces expansion of regulatory $\mathrm{T}$ cells in the fetus, which likely contributes to the reduced risk of T1D in children with maternal vs. paternal diabetes.

\section{Intrauterine infections}

Intrauterine infections have been proposed to be related to an enhanced risk of T1D. The classical example is the congenital rubella syndrome, in which $10-20 \%$ of the offspring have been reported to develop diabetes $[25,26]$. A closer look at the data available suggests, however, that many of these 
patients have atypical diabetes. In our own study including 37 patients exposed to congenital rubella, only one had diabetes [27]. None of the patients had signs of beta cell autoimmunity. Maternal enterovirus infections during pregnancy have also been implicated to be a risk factor for T1D. A Swedish study reported that the mothers of offspring who later presented with T1D had signs of a recent enterovirus infection in a sample taken at delivery more frequently than control mothers [28]. A Finnish study based on the largest data set so far analyzed revealed a moderate association between serological evidence for a maternal enterovirus infection and risk of early T1D in the offspring [29].

\section{Fetal immune education}

The immune system starts to function already in utero. The DIABIMMUNE study set out to test the hygiene hypothesis by studying infants and young children in three adjacent countries with a conspicuous difference in the standard of living and hygiene as well as in the incidence of T1D and the frequency of other immune-mediated phenomena [30]. We analyzed the whole blood transcriptome in cord blood from newborn infants in Finland, Russian Karelia, and Estonia. Genome-wide transcriptomic analysis revealed that the gene expression profiles were conspicuously different in cord blood from infants in Russian Karelia when compared to Finnish infants [31]. The transcriptome of infants born in Estonia were more similar to infants born in Finland than to transcriptomes of those of Russian-Karelian infants. In the latter, the genes involved in the activation of the innate immune system were clearly upregulated. When comparing the data with previous studies that had analyzed the gene expression in newborn infants and 1-year-old children, it was obvious that the cord blood of Russian-Karelian infants had gene expression profiles characteristic of a more mature immune system than Finnish and Estonian infants. These observations indicate that immunomodulation by environmental factors occurs already during fetal life.

\section{Maternal nutrition}

Maternal diet during pregnancy has been studied in relation to later risk of T1D in the offspring [32,33]. No convincing associations have emerged. A Norwegian retrospective study reported that mothers of children with T1D consumed less cod liver oil during their pregnancy [34]. Cod liver oil contains high concentrations of vitamin $\mathrm{D}$ and long-chain $n-3$ fatty acids such as docosahexaenoic acid (DHA) and eicosapentaenoic acid (EPA). These fatty acids are considered to have antiinflammatory properties. A subsequent prospective study was unable to observe any association between the T1D risk in the offspring and the concentrations of DHA, EPA, and other fatty acids in maternal serum obtained in late pregnancy [35].
Vitamin D status may have an impact on the development of the fetus. The studies exploring the possible association between maternal vitamin D intake and circulating vitamin D concentrations during pregnancy have resulted in conflicting conclusions. In the Finnish Diabetes Prediction and Prevention (DIPP) study, there was no association between maternal dietary intake of vitamin $\mathrm{D}$ from food or supplements during pregnancy and later signs of islet autoimmunity or overt T1D in the offspring [36]. A Norwegian study reported an association between higher serum 25-hydroxyvitamin D concentrations in samples taken in late pregnancy and a reduced risk of T1D in the children [37]. In contrast, a Finnish study was unable to find such an association based on samples collected during the first trimester of pregnancy [38].

\section{Fetal growth}

A meta-analysis from 2010 suggested a weak but statistically significant association between high birth weight and later T1D [39]. The data on the impact of maternal weight gain during pregnancy is contradictory. A Norwegian study suggested that a higher maternal weight gain is associated with an increased risk for T1D in the offspring [40], whereas a Finnish study was unable to detect any association [41]. High birth weight may be associated with enhanced insulin secretion, and that may render the beta cells more susceptible to damage. Prematurity seems to be associated weakly with increased risk of T1D in the offspring [42].

\section{Other factors}

Most studies analyzing the association between maternal smoking and risk of T1D in the offspring have reported that smoking reduces the risk of T1D [42]. It has been speculated that maternal smoking might have modulatory effects on the immune system or DNA methylation. Older maternal age at delivery has been reported to be associated with an increased T1D risk in the offspring [43]. We have, however, not been able to see any significant association between later risk of islet autoimmunity in the offspring and maternal smoking or age [44]. Birth order could be anticipated to affect the risk of T1D based on the hygiene hypothesis. Birth order associations with T1D risk have, however, been observed to be weak and heterogeneous indicating that the effect is minor [45]. Mode of delivery may modulate the risk of T1D, as Cesarean section has been reported to be associated with an increased risk of T1D in the offspring [46]. The German BABYDIAB found that cesarean section is associated with a higher risk of progression from beta cell autoimmunity to clinical T1D but not with seroconversion to autoantibody positivity [47]. Cesarean section affects the developing intestinal microbiome in the offspring and may thereby modulate the risk of T1D [48]. We have, however, observed that about $20 \%$ of vaginally born 
infants have a gut microbiota similar to that seen in infants born with cesarean section and characterized by a dearth of Bacteroides species over the first 10-12 months of life [49].

\section{Postnatal life}

\section{Early feeding}

Early nutrition provides essential exogenous exposures during the first year of life, a time window during which the first T1D-associated autoantibodies often appear [50]. Breastfeeding has been reported to protect against T1D, predispose to the disease or have no effect on disease risk [51]. A series of prospective studies assessing the association between breastfeeding and the development of beta cell autoimmunity have concluded that breastfeeding is not associated with the emergence of diabetes-associated autoantibodies [44, 52, 53]. Some studies suggest, however, that a short duration of breastfeeding is associated with the appearance of signs of beta cell autoimmunity $[54,55]$. These inconsistent observations may be due to several reasons. Many studies have not differentiated between exclusive and total breastfeeding, which might be important. There are also clear national and cultural differences in the breastfeeding practices.

Early exposure to cow's milk proteins (i.e., conventional infant formulas) has been assessed in relation to later risk of beta cell autoimmunity and overt T1D. The duration of exclusive breastfeeding is usually inversely related to the age at introduction of infant formula. These surveys have also generated contradictory results [51], mainly from that point of view that some studies have suggested that early introduction of cow's milk increases the risk of beta cell autoimmunity $[54,55]$ and T1D [56-58] while others have found no association between those two phenomena [59,60]. When assessing simultaneously the role of age at introduction of cow's milk and that of the duration of breastfeeding, starting cow's milk early turned out to be the more dominant risk factor for T1D in a Finnish case-control study [57]. Several explanations have been offered for the inconsistent results. Although milk formula is usually the first foreign food source in the infant period all over the world, the proportion of babies first exposed to milk-based formulas varies between countries and cultures. The kind of solid foods which are given to those infants who are not first exposed to milk formula does vary between different countries. For example, a substantial proportion of U.S. infants are first given cereals while this is very rare in Finland [44, 52]. There is also substantial variation in the use of partly or extensively hydrolyzed formulas in normal infants between different countries, which can be expected to be an important confounder, when analyzing the relationship between introduction of cow's milk and the appearance of islet autoimmunity and T1D.
An association between early introduction of cereals in infancy and the appearance of early islet autoimmunity has been reported by two prospective surveys. The American study indicated that both early (before the age of 4 months) and late exposure (at the age of 7 months or later) to cereals were related to an increased risk of beta cell autoimmunity [52] while the German survey suggested that an increased risk was linked to exposure to cereals before the age of 3 months [53]. The U.S. study also implied that both gluten-containing and non-gluten containing cereals were related to an enhanced risk for islet autoimmunity. Early introduction of cereals is not recommended in guidelines for infant nutrition in any developed countries and happens only infrequently. For example, Finnish infants are rarely given any cereals before the age of 4 months. Prospectively analyzed DIPP data showed no relationship between early or late start of cereals and appearance of advanced beta cell autoimmunity, i.e., positivity for at least two T1D-associated autoantibodies out of four analyzed [44].

Our DIPP data revealed that early introduction of fruits and berries as well as of roots is related to enhanced risk for advanced islet autoimmunity [44]. A more recent survey including more subjects with two or more diabetes-associated autoantibodies from the DIPP cohort confirmed that high intake of fruit and berry juices was associated with an increased risk of advanced beta cell autoimmunity [61]. That study observed also that the risk of seroconversion to multiple autoantibodies was modestly increased by the intake of milk-based infant formulas and subsequent intake of milk products,

Stene et al. observed in 2003 that the use of cod liver oil in infancy was associated with a reduced risk of T1D [62]. Cod liver oil is composed of high concentrations of both $n$-3 polyunsaturated fatty acids and vitamin D. A case-cohort analysis based on the DAISY study implied that the intake of $n-3$ fatty acids between the ages of 1 and 6 years was related to a reduced risk of beta cell autoimmunity [63]. In a recent study, we observed that higher serum pentadecanoic, palmitic, palmitoleic acids, and DHA at the age of 3 and 6 months decreased the risk of beta cell autoimmunity while higher arachidonic acid:DHA and $n-6: n-3$ acid ratios increased the risk of islet autoimmunity [64]. These observations suggest that fish-derived fatty acids may be protective, particularly during infancy and fatty acids consumed during breastfeeding may provide protection against T1D-associated autoimmunity.

There have been a few pilot intervention trials that have modified the infant diet. Two hundred thirty Finnish infants with HLA-defined predisposition to T1D were randomized to weaning to either a highly hydrolyzed formula or a conventional cow's milk based formula before the age of 6-8 months in the pilot of the Trial to Reduce IDDM in the Genetically at Risk (TRIGR). The families were advised not to give any food products containing cow's milk or bovine proteins to their infant during the intervention period. As a consequence of the intervention, the introduction of intact cow's milk proteins 
was postponed by several months in the active intervention group. The dietary intervention in infancy resulted in a reduction in most signs of beta cell autoimmunity in the range of $50-60 \%$ by a median age of 10 years [65]. There was a significant decrease in the cumulative incidence of ICA, IA-2A, and positivity for at least one of the five autoantibody reactivities analyzed. In the full-scale TRIGR study with 2159 randomized participants, we were, however, unable to see any difference in the cumulative incidence of multiple $(\geq 2)$ autoantibodies after a median observation up to the age of 7 years [66]. The full-scale TRIGR will reach its final endpoint in 2017, i.e., clinical T1D by the age of 10-14 years.

The German BABYDIET study was designed to assess whether delaying the introduction of gluten beyond 12 months of age will decrease the risk of beta cell autoimmunity in young children at enhanced T1D risk. The intervention did not result in any difference in the cumulative incidence of diabetes-associated autoantibodies or clinical T1D between the two groups [67]. A TrialNet-based pilot trial, called "The Nutritional Intervention for the Prevention of Type 1 Diabetes (NIP)" was started some years ago to test the feasibility of a full-scale trial addressing the hypothesis that dietary supplementation with DHA during pregnancy and in infancy will prevent beta cell autoimmunity in infants at risk [68].

Insulin is a crucial autoantigen in T1D as it is the only beta cell specific autoantigen in postnatal life. IAA are the first or among the first autoantibodies to appear when the disease process resulting in T1D is initiated in young children [5, 69]. The frequency of IAA is also considerably higher among young children at the diagnosis of T1D than among older children and adults [70]. As cow's milk formulas generally are the first and most common dietary source of foreign, complex proteins that an infant is exposed to in Western countries, we asked whether early exposure to conventional formula leads to an immune response to bovine insulin detectable in formulas and differing from human insulin by three amino acids, two in the A chain and one in the B chain. In this study we observed that the infants who were exclusively breast-fed for a minimum of 3 months had clearly lower IgG class antibodies to bovine insulin than those who were exposed to formula before that age [71]. The observation of the study participants continued up to the age of 18 months. The follow-up revealed that the $\operatorname{IgG}$ class insulin antibodies started to slowly decrease after the age of 3 months as a sign of the development of oral tolerance in those infants who were given formula before the age of 3 months. In contrast, in those fully breastfed at least to the age of 3 months, the antibody levels increased up to the age of 12 months, and thereafter they started to level off. That antibody profile was expected, since these subjects were exposed to cow's milk-based products, mostly formula, at some point in the infant period. The study cohort comprised a small group of infants $(n=11)$ who developed early signs of islet autoimmunity. In these children, the IgG antibodies to bovine insulin rose continuously. This increase may partly be due to the emergence of IAA, because human insulin cross-reacts considerably with bovine insulin in the insulin antibody assays. The rise in IgG antibodies to bovine insulin remained, however, significant even after adjustment for the IAA titres. These observations suggest that those young children who develop early signs of islet autoimmunity seem to lack the capacity to develop oral tolerance to bovine insulin. One may speculate that the initial immune response to bovine insulin may later be diverted into a response targeting human insulin in such children.

We conducted a pilot intervention trial employing weaning to an insulin-free formula in Finland among infants with HLA-defined predisposition to T1D. Three-year follow-up data showed that weaning to such a formula during the first 6 months of life decreased the cumulative incidence of diabetes-predictive autoantibodies by more than $60 \%$ when compared to infants weaned to a conventional formula [72]. Gluten or other cereal-derived proteins have been implicated as candidate driving antigens in T1D. Two small-scale pilot intervention studies have been carried out in first-degree relatives testing positive for diabetes-associated autoantibodies to assess whether gluten elimination modulates the natural course of islet autoimmunity. The autoantibody titres did not change significantly during the intervention period or during the re-exposure period in those trials $[73,74]$.

\section{Supplements: vitamin D and probiotics}

A series of retrospective studies have suggested that the lack of vitamin D supplementation in infancy enhances the subsequent risk of T1D. A European case-control study from seven centers suggested that supplementation with vitamin D in infancy resulted in a decreased disease risk [75]. A Finnish birth cohort study reported that both regular and irregular high-dose supplementation with vitamin D in infancy (2000 IU/day at that time vs. $400 \mathrm{IU} / \mathrm{d}$ currently) was associated with a reduced T1D risk when compared to no supplementation [76]. In a prospective study based on the DIPP cohort we have analyzed the circulating concentrations of 25-hydroxyvitamin D concentrations in $126 \mathrm{~T} 1 \mathrm{D}$ progressors and the same number of matched control children starting in early infancy up to the diagnosis of T1D in cases and to the corresponding age in the controls. We found no significant differences between the cases and controls in the vitamin D concentrations at any age [77]. This speaks against a crucial role of low vitamin D concentrations or deficiency as a risk factor for T1D.

The TEDDY (The Early Determinants of Diabetes in the Young) study explored whether the use of probiotics in infants has any effect on the seroconversion rate to positivity for diabetes-associated autoantibodies. It turned out that probiotic supplementation during the first 4 weeks of life was associated 
with a decreased risk of islet autoimmunity when compared to later probiotic supplementation or no probiotic supplementation [78]. This association was observed in infants with the HLA DR3/DR4 high-risk genotype while it was absent in infants carrying other genotypes. Future studies will reveal whether this is a true association or represents a proxy of some other characteristic.

\section{Postnatal growth}

Accelerated weight gain in the infant period has repeatedly been implicated to be a risk factor for T1D later in childhood [14]. Increased weight gain induces endoplasmic reticulum stress in beta cells, which may augment innate immune responses [79]. This is a possible mechanism mediating the effect of rapid weight gain on T1D risk. Finnish studies have reported that those children who developed T1D subsequently were not only heavier but also taller already in infancy without any significant differences in birth weight or length [80, 81]. The DAISY study reported that accelerated height velocity may be involved in the progression from genetic diabetes susceptibility to beta cell autoimmunity, and further to clinical T1D in prepubertal children [82].

\section{Early infections}

Infections, especially respiratory infections, in the infant period have recently been observed to be a risk factor for islet autoimmunity and progression to T1D [30, 83-85]. These findings may reflect either differences in microbial exposures or early immunological aberrations making diabetes-prone children more susceptible to infections.

In the DIPP study, we have observed a close temporal association between the appearance of the first diabetesassociated autoantibodies and enterovirus (EV) infections $[86,87]$. We have also found an apparent temporal variation in the appearance of the first signs of beta cell autoimmunity fitting very well into the annual pattern of EV infections with the highest rate in the fall and winter [88]. These findings suggest that a diabetogenic EV infection is the most likely trigger of islet autoimmunity in a considerable proportion of cases developing autoantibodies early in life. Later, we conducted a systematic study of neutralizing antibodies to $41 \mathrm{EVS}$ from the first autoantibody positive samples in 183 DIPP children testing persistently positive for two autoantibodies and in more than 360 autoantibody-negative control children. The latter were matched with the cases for gender, HLA genotype, and date and location of birth. Neutralizing antibodies are serotype specific and relatively persistent, and consequently our analyses revealed which infections the child had experienced before their seroconversion. The results showed that the cases had more infections caused by Coxsackie virus B1 (CBV1) and fewer infections caused by B3 and B6 [89].
Subsequently, we determined the neutralizing antibodies to the six CBV serotypes in two additional samples from the same individuals (i.e., the samples obtained 12 and 6 months before seroconversion). The data revealed that there was a rising odds ratio for a CBV1 infection over time with a significantly increased risk in the sample taken at the time of seroconversion. When the 119 children who have progressed to overt T1D were analyzed in a subanalysis including their controls, the outcome was identical. These observations suggest that CBV1 is a likely trigger of islet autoimmunity and of the disease process resulting in overt T1D.

The implicated link between beta cell autoimmunity and $\mathrm{EV}$ infections has been questioned, since most of the supportive data have been generated by Finnish studies, and two other prospective studies, i.e. the German BABYDIAB study and the American DAISY study, failed to show any association between EV infections and beta cell autoimmunity [90, 91]. At least three critical issues have, however, to be considered when assessing whether any prospective study is able to provide informative data in this context. The first one is the size of the study cohort and the number of children who develop signs of islet autoimmunity; factors critical for the statistical power of the study. A second crucial consideration is the study design and the sampling interval. Long sampling intervals definitely hamper the possibility to detect EV infections from collected samples. In the BABYDIAB study CBV antibodies were analyzed from serum samples obtained at the age of 9 months, 2, 5, and 8 years, and in DAISY the samples were collected at the age of 9 months, 15 months, 2 years, and then once a year. In the DIPP study, the samples have been obtained with an interval of 3-6 months up to the age of 2 years and then with an interval of 6-12 months. The third critical point is related to the type of samples collected and the methods used for the detection of EV infections. A more recent analysis of 140 autoantibody-positive children from the DAISY study indicated that progression to overt T1D increased after an invasive EV infection characterized by the presence of viral DNA in the peripheral circulation [92]. No correlation was observed by Simonen-Tikka et al. between the presence of EV in stool samples and the development of beta-cell autoimmunity during the first 12 months of life in the German BABYDIET study [93]. The series comprised, however, only 22 autoantibody-positive subjects. A considerably larger series of young DIPP children (129 cases) who seroconverted to positivity for multiple autoantibodies revealed that enteroviral RNA in stools are related to the development of beta-cell autoimmunity with a time lag of several months [94]. The observation that all enteroviruses associated with islet autoimmunity and progression to T1D belong to the CBV family comprising six serotypes raises the possibility to develop an antidiabetogenic CBV vaccine [95]. Such an effort has been initiated. 
The list of other viruses implicated to be associated with T1D includes rotavirus, cytomegalovirus, mumps, rubella, Ljungan virus, and retroviruses [96]. Australian studies have reported molecular homology between the VP7 protein of rotavirus and T cell epitopes in the IA-2 molecule and in the $65 \mathrm{kD}$ isoform of $\operatorname{GAD}[97,98]$. In a prospective study of infants genetically predisposed to T1D, they observed that the emergence of diabetes-associated autoantibodies was associated with significant rises in rotavirus antibody titres, indicating that rotavirus infections may induce islet autoimmunity in genetically susceptible infants [99]. A Finnish prospective study showed that $16 \%$ of infants and young children with HLA-defined predisposition to T1D experienced a rotavirus infection during the 6-month window preceding the detection of the first signs of beta cell autoimmunity while $15 \%$ of the control subjects matched for gender, birth date, delivery hospital, and HLA genotype had signs of a rotavirus infection during the corresponding time period [100]. That observation failed to support the role of rotavirus infections as triggers of beta cell autoimmunity. No recent data indicate that any of the other viruses listed could function as a trigger of islet autoimmunity and/or the diabetic disease process.

\section{Intestinal microbiome}

The earlier assumption that fetuses are born from a sterile environment has been challenged by the observation that the placenta might have its own rich microbiota and that maternal infections, especially those affecting the urinary tract and gingivae, induce changes in the early colonization of the neonate and the bacterial composition of their meconium [101]. These observations remain controversial, however, as it cannot currently be excluded that the microorganisms detected in the placenta and neonatal meconium result from contamination [102].

As mentioned earlier, the route of delivery has an effect on the composition of an infant's gut microbiota [103-106]. Children who are delivered vaginally receive an ample load of maternal vaginal microbiota, such as Lactobacillus, Prevotella and Sneathia, during the delivery, whereas the early colonizers of infants born by cesarean section are typical of skin, medical equipment and the air of the neonatal ward, such as Staphylococcus, Corynebacterium, and Propionibacterium [106]. Being born by cesarean section decreases the overall microbial diversity, as well as the abundance and diversity of the Bacteroidetes phylum, in infants [107, 108].

Initial observations in the DIPP study implied that the diversity of the gut microbial composition is reduced in children who later progress to T1D [109]. Sensitive readout of gut microbial variation along with genetic and environmental factors may also help explain how the gut microbial composition affects host physiology. A recent metagenomics analysis of stool samples from DIPP progressors and matched nondiabetic controls revealed that genes involved in carbohydrate metabolism, adhesion, motility, phages, sulfur metabolism, and stress responses were more prevalent in cases whereas genes with roles in DNA and protein metabolism, aerobic respiration, and amino acid synthesis were more frequent in the control children [110]. Mining 16S rRNA data from these datasets showed a higher proportion of butyrate-producing and mucin-degrading bacteria in controls compared to cases, while the abundance of those bacteria that produce short chain fatty acids other than butyrate were higher in cases. These observations indicate that a consortium of lactate- and butyrate-producing bacteria in a healthy gut induce a sufficient amount of mucin synthesis to maintain gut integrity. In contrast, non-butyrate-producing lactate-utilizing bacteria prevent optimal mucin synthesis, as seen in autoimmune subjects. In another study, 11 infants developing at least two diabetesassociated autoantibodies early and 22 matched controls were observed from birth up to the age of 3 years with monthly stool samples [111]. Four out of the 11 autoantibody-positive children progressed to clinical T1D. In that study, we observed that microbial metabolic pathways remain remarkably stable throughout infancy. The presentation of T1D was preceded by a drop in community diversity and a spike in inflammationassociated species and metabolic pathways.

In a recent study, we have analyzed the development of the gut microbiome over the first 3 years of life in Finnish, Estonian, and Russian Karelian children [112]. Finnish children have a six times higher incidence of T1D than RussianKarelian children [113]. Moreover, we have observed that the frequency of a series of immune-mediated diseases and phenomena, such as celiac disease, thyroid autoimmunity, and atopic sensitization is 16 times lower in Russian Karelia than in Finland [114]. In the microbiome work, we observed in the Finnish infants that the Bacteroides genus was dominant, while that genus was considerably less abundant in the Russian-Karelian peers. It is known that lipopolysaccharide (LPS) from Bacteroides species is generally less immunostimulatory than E. coli-derived LPS. This got us to purify LPS from a number of bacterial species identified in the cohort. We noted that LPS purified from Bacteroides dorei, the highest-enriched species in Finland compared to Russia, failed to stimulate in vitro toll-like receptor 4 (TLR4) and the secretion of a series of cytokines from human peripheral blood mononuclear cells (PBMCs). In addition, the Bacteroides dorei-derived LPS act as a TLR4 antagonist, preventing stimulation of TLR4 by E. coli-derived LPS. Notably, B. dorei has recently also been associated with the appearance of signs of beta cell autoimmunity in children at risk for T1D [115]. Our observations indicate that early colonization by an immunoinhibitory microbiota in Finnish infants may counter the immune stimulation by $E$. coli LPS, fostering susceptibility to immune-mediated diseases, T1D included, in Finland. The putative differences in the early education of the immune system might affect the degree of beta cell damage and the 
transition from innate immunity to adaptive immunity resulting in islet autoimmuniy in infants at risk [116].

Moreover, we noted that the Russian Karelian infants had an increased abundance of Bifidobacteria strains except for Bifidobacterium breve, which were more frequent in Finnish infants. All in all, the intestinal microbiota in Finnish infants was characterized by dysbiosis including a decreased abundance of most Bifidobacteria species and an increased abundance of Bacteroides species.

\section{Use of antibiotics}

Young children in developed countries are frequently exposed to antibiotic treatment. A recent Danish study did not show any association in general between frequent antibiotic use and T1D risk [117]. However, having five or more antibiotic prescriptions in the first 2 years of life was associated with an enhanced risk of T1D. This association appeared to be driven by exposure to broad-spectrum antibiotics within the second year of life. Treatment with broad-spectrum antibiotics during the first 2 years of life was related to an increased rate of T1D during the following 13 years in another Danish study [118]. This was true for children born by cesarean section but not for those born vaginally.

\section{New data generated by -omics}

The recently introduced-omics technologies generate a lot of data, which requires access to high quality bioinformatics services. Especially combined analyses of -omics data is still in its infancy.

\section{Epigenome}

Epigenetic modifications provide a mechanism for environmental cues to integrate and impact at the cellular level [119]. DNA methylation is determined partly genetically but also by many environmental factors implicated in T1D (dietary components, antibiotics, and microbiome products, e.g., short chain fatty acids). In addition to DNA methylation, histone modifications are also involved in T1D pathogenesis [120], but our present understanding of epigenetic dynamics in autoimmune disease is limited. Epigenetic modifications have turned out to be more reversible and dynamic than previously thought. Dynamic epigenetic modifications control the development, differentiation, and activation of immune cells [119]. Periconceptional development may be the most critical time when the environment can induce epigenetic changes in reproductive cells that are associated with a higher risk of disease in future generations. Father's BMI may in fact have a greater impact than mother's BMI on body fat in children in the normal population [121]. The impact of paternal obesity or type 2 diabetes on the incidence of type 2 diabetes in the offspring has also been established in the Pima Indians who have a high risk for type 2 diabetes [122]. In experimental models, this transgenerational risk from the father is mediated via epigenetic changes in sperm [123]. Such paternallyderived epigenetic effects might also contribute to the higher risk of T1D in the offspring of paternal as opposed to maternal probands as discussed earlier [22, 23]. New epigeneticimmune signatures are potential biomarkers of risk for T1D and umbilical cord blood may reveal signatures that predict risk of T1D, if the pathogenic processes begin prenatally. An example of an epigenetic-immune biomarker in early development is the recent report of an immune signature of food allergy in human cord blood [124]. Dynamic epigenetic modifications indicate gene regulatory mechanisms that are reversible, so they may provide targets for novel therapies. For example, the enzymes catalyzing epigenetic modifications could potentially be developed into therapeutic agents.

\section{Transcriptome}

Transcriptomics has been applied to search for changes in the peripheral blood of children at various stages of the diabetic disease process. The initial studies mainly compared individuals affected by T1D to controls, but more recently samples from autoantibody positive children have been analyzed [125]. One aim is to identify potential markers that could be used to distinguish those who may progress rapidly to T1D from the slow progressors. Jin and co-workers performed microarray analysis of PBMCs from antibody positive children who developed T1D and compared these with the results in antibody positive children who had not yet progressed to T1D within the time span of several additional years [124]. The children compared were matched for age, gender, genetic risk and incidence of disease in family members. Reverse transcription polymerase chain reaction of peripheral blood total RNA from antibody positive progressors and their antibody positive matched non-progressors were applied to validate differentially abundant genes. These profiling and validation analyses generated a panel of five genes (BACH2, IGLL3, TXNRD5, CDC20, and EIF3A) that might serve as potential biomarkers for risk stratification in antibody positive subjects and may play a role in the pathogenesis of T1D.

The first transcriptomics analysis of the DIPP children was a proof-of-concept study demonstrating the value of analyzing longitudinal whole blood samples from children who develop autoantibodies or T1D and their carefully matched controls [126]. Whereas the number of cases and controls was limited, the analysis showed differential expression of 520 probe sets between the cases and controls, several of which belonged to pathways operative in the immune system. The longitudinal samples also demonstrated that the responses were dynamic. Encouraged by these observations, we increased the number 
of subjects and samples to conduct further transcriptome analysis [127]. We found that gene expression signatures reflecting immune system activation were seen already before the appearance of T1D-associated autoantibodies. A more detailed analysis of these data showed that some 300 probes were detected as differentially expressed between the seroconverted children and their matched controls. Among the upregulated genes the retinoic acid inducible gene 1 (RIG-I)-like receptor signaling and cytosolic DNA-sensing pathways were enriched before the diagnosis of overt T1D. During this period, the differentially expressed genes were also enriched with genes localized within the T1Dassociated susceptibility loci and included the major histocompatibility complex class I C (HLA-C), protein tyrosine phosphatase, non-receptor type 22 (PTPN22), and IKAROS family zinc finger 1 (IKZF1). We discovered that a distinct interconnected IRF7-centered transcriptional network was activated in T1D progressors. This network of 32 genes also included STAT1, STAT2, and TRIM22 - all involved in interferon (IFN) and innate immunity responses. In addition, altogether 95 unique transcription factors were differentially expressed in subjects who progressed to clinical T1D.

To recognize transcriptional signatures typical for distinct phases of the autoimmune process, the data was analyzed according to several time windows (i.e., before seroconversion, at seroconversion, 6-18 months after seroconversion, 1-2 years before T1D diagnosis, and at the T1D diagnosis). In the time-windows before, at, or 6-18 months after seroconversion 604,263 , and 1578 probes were identified as differentially expressed, respectively; 103 probes were recognized that were common to all three time windows. During the intervals of 1-2 years before clinical diagnosis and at clinical diagnosis, 1609 and 876 probes were differentially expressed between the cases and controls. Interestingly, the cytokine receptor-cytokine interaction pathway was one of the upregulated functions at the diagnosis of T1D. To summarize, the changes were highly dynamic relative to different stages of T1D pathogenesis, suggesting that different transcriptional signatures are found depending on the stage of progression of the disease. However, a module consisting of IFN-induced transcripts was constantly detected in every time-window.

In the study by Ferreira et al. [128], which appeared back to back with the data from the DIPP study, an IFN inducible signature was identified in vitro in PBMCs from healthy controls, and then evaluated in terms of the onset of autoimmunity and progression to clinical T1D, utilizing samples from the German BABYDIET study, a prospective birth cohort of children at high-risk of developing T1D. In line with the observations from the DIPP study, an IFN signature was seen already before seroconversion in children developing T1D. It was speculated that upregulation of IFN could be linked to findings indicating an increased risk of islet autoimmunity conferred by viral infection, and especially with the pathogenic role of CBVs in the induction of islet autoimmunity [88].

\section{Metabolome/lipidome}

A seminal publication by Oresic et al. identified distinctive metabolite patterns in children who later developed T1D [129]. A high number of samples were analyzed thanks to the rapid analysis times achievable for polar metabolites with two-dimensional gas chromatography coupled to time-offlight mass spectrometry $(\mathrm{GC} \times \mathrm{GC}$-TOFMS $)$ and the use of ultra-high performance liquid chromatography (UHPLC) together with electrospray MS for lipids. Using UHPLC-MS, lipid profiles were analyzed for 56 children who progressed to T1D and 73 controls from a set of 1196 samples. The authors observed decreased serum levels of succinate and phosphatidylcholine (PC) at birth and decreased and declining levels of serum triglycerides and multiple phospholipids during the follow up. They suggested based on the decreased PC levels that the progressors may be choline deficient from birth. Furthermore the observed differences might reflect differences in the gut microbiome of these children, which in turn may be related to the maternal diet or intestinal microbiota during pregnancy. The overall model generated from these data indicated that the differences may affect the immune system in the offspring and that metabolic dysregulation precedes islet autoimmunity.

In later work from the same group, the importance of in utero effects was considered in samples analyzed from a Swedish study population (DiPiS) [130]. The authors found that the cord-blood lipidome was altered in children diagnosed with T1D before the age of 8 years when compared to control children matched for HLA risk, sex, and date of birth, as well as maternal age and gestational age. In concordance with their previous observations they also found a significant reduction in cord-blood PCs and phosphatidylethanolamines in children diagnosed with T1D before 4 years of age. They underlined the potential role of phospholipids as mediators of the immune system that might be involved in the early induction of beta cell autoimmunity, and suggested that lipidomics of umbilical cord blood may be applied to identify children at enhanced risk for T1D. In a Finnish study based on DIPP participants, Oresic et al. analyzed the cord serum lipidome in infants who progressed to T1D relative to matched healthy controls and those who developed autoantibodies but did not develop clinical T1D during prospective observation [131]. The controls were matched with the cases for sex, HLA-DQB1 genotype, city of birth, and period of birth. These analyses revealed distinct cord blood lipidomic profiles in T1D progressors characterized by decreased levels of the major choline containing phospholipids, in concordance with previous observations from the DIPP [129] and 
DiPiS studies [130]. Based on these findings, the authors concluded that the decrease in choline-containing phospholipids in cord blood is specifically associated with early progression to T1D but not with development of islet autoimmunity per se.

\section{Proteome}

Most earlier proteomics studies related to T1D have focused on the serum proteome in newly diagnosed patients and healthy controls [132-134]. However, recent prospective sample collections have allowed the characterization of temporal changes in the serum proteome of children en route to T1D. Utilizing DIPP samples Moulder et al. have applied quantitative MS-based proteomics approaches to characterize the time course from early infancy to seroconversion and diagnosis, comparing these with measurements from healthy controls [135]. Two methods have been applied, i.e., an 8-plex variant of isotope tagged relative and absolute quantification (iTRAQ) reagents and a label-free approach for quantitative proteomics (LFQ). Together the two methods generated quantitative profiles in the order of 250 proteins across multiple samples and subjects.

Among the T1D progressors, an increasing abundance of proteins related to acute inflammatory response, complement activation, humoral and adaptive immune response was detected. Remarkably, differences in the abundance of the complement proteins were often seen from hierarchical clustering of the data. To achieve an overview of how the relative abundance of the proteins relate to the complement system, correlations were calculated for the proteins observed in the cases and controls relative to one of the central complement proteins, complement 5 . This analysis suggested that the T1D progressors had more conspicuous changes in complement proteins, in proteins of the membrane attack complex and antigen-antibody complex in particular.

A rank product analysis was applied to identify proteins that were differentially abundant in specific time windows relative to autoantibody seroconversion and T1D diagnosis. A panel of differential abundant proteins was recognized including markers observed prior to seroconversion. Using the top scoring pair method, two proteins (APOC4 and AFAM) were found to classify the subjects into progressors and nonprogressors with a high success rate. Consequently, these results demonstrated the possibility to identify children at risk on the basis of their serum protein profiles.

\section{Conclusions}

The current status suggests that there are a lot of environmental factors operative in early life that have been implicated to contribute to the risk of T1D. There are, however, very few environmental and host-related determinants that have been unequivocally confirmed to act as a susceptibility or protective factor in relation to the development of T1D. In most areas, there are controversial data making it difficult to draw firm conclusions. The observation that maternal T1D reduces the risk of T1D in the offspring by $50-70 \%$ has been confirmed repeatedly. Increasing data is accumulating indicating that an early diabetogenic CBV may be a trigger of islet autoimmunity at least in a part of those children who progress to clinical T1D. Emerging data suggest that increased concentrations of $n-3$ fatty acids in infancy, most likely due to an enhanced intake, may reduce the risk of T1D. Intestinal dysbiosis and a reduced microbial diversity seem to be involved in the progression from islet autoimmunity to clinical T1D.

The fact that the first signs of beta cell autoimmunity may appear already during the first year of life and that the overwhelming majority of those children who progress to overt T1D before puberty seroconvert to positivity for T1D-associated autoantibodies during their first 3 years of life [136] support strongly the view that T1D is a disease of developmental origin. So far the possible role of fetal life has not been assessed in depth emphasizing the need to study that period more closely. The Australian ENDIA (Environmental Determinants of Islet Autoimmunity) has embarked on that route by observing at risk offspring from early pregnancy through childhood to assess the relationship between the genome, epigenome, microbiome, metabolome, and environment in the development of beta cell autoimmunity [137]. There are also other efforts aimed at assessing the importance of the fetal period in relation to the risk of later T1D. The -omics technologies are expected to generate novel information on the process leading to overt T1D. They have also the potential to provide new biomarkers to monitor the disease process and the effect of possible interventions aimed at halting the disease process. There is definitely a need to focus on early life to learn more about the origin of T1D.

Funding information Research that is relevant for this review is and has been supported by the following grants: Juvenile Diabetes Research Foundation International (grants 4-1998-274, 4-1999-731, 4-2001-435), European Union (grant BMH4-CT98-3314), Novo Nordisk Foundation, Academy of Finland (Centre of Excellence in Molecular Systems Immunology and Physiology Research 2012-2017, Decision No. 250114), Special Research Funds for University Hospitals in Finland, Sigrid Juselius Foundation, Finska Läkaresällskapet, and Medicinska understödsföreningen Liv och Hälsa.

\section{Compliance with ethical standards}

Conflict of interest Mikael Knip is an advisor to Vactech Oyj and Provention Bio, Inc. The other authors declare that they have no conflict of interest. 


\section{References}

1. Knip M (2002) Natural course of preclinical type 1 diabetes. Horm Res 57(Suppl. 1):6-11

2. Knip M, Korhonen S, Kulmala P et al (2010) Prediction of type 1 diabetes in the general population. Diabetes Care 33: 1206-1212

3. Knip M, Siljander H, Ilonen J, Simell O, Veijola R (2016) Role of humoral beta-cell autoimmunity in type 1 diabetes. Pediatr Diabetes 17(Suppl. S22):17-24**This paper is a major source document for the current article

4. Ziegler AG, Rewers M, Simell O et al (2013) Seroconversion to multiple islet autoantibodies and risk of progression to diabetes in children. JAMA 309:2473-2479

5. Kimpimäki T, Kulmala P, Savola K et al (2002) Natural history of beta-cell autoimmunity in young children with increased genetic susceptibility to type 1 diabetes recruited from the general population. J Clin Endocrinol Metab 87:4572-4579

6. Kukko M, Kimpimäki T, Korhonen S et al (2005) Dynamics of diabetes-associated autoantibodies in young children with human leukocyte antigen-conferred risk for type 1 diabetes recruited from the general population. J Clin Endocrinol Metab 9:2712-2717

7. Siljander H, Simell S, Hekkala A et al (2009) Predictive characteristics of diabetes-associated autoantibodies among children with HLA-conferred disease susceptibility in the general population. Diabetes 58:2835-2842

8. Ilonen J, Hammais A, Laine A-P et al (2013) Patterns of $\beta$-cell autoantibody appearance and genetic associations during the first years of life. Diabetes 62:3636-3640

9. Krischer JP, Lynch KF, Schatz DA et al (2015) The 6 year incidence of diabetes-associated autoantibodies in genetically at-risk children: the TEDDY study. Diabetologia 58:980-987

10. Barnett AH, Eff C, Leslie RDG, Pyke DA (1981) Diabetes in identical twins: a study of 200 pairs. Diabetologia 20:87-93

11. Kaprio J, Tuomilehto J, Koskenvuo M et al (1992) Concordance for type 1 (insulin-dependent) and type 2 (non-insulin-dependent) diabetes mellitus in a population-based cohort of twins in Finland. Diabetologia 35:1060-1067

12. Patterson CC, Gyürüs C, Rosenbauer J et al (2012) Trends in childhood type 1 diabetes incidence in Europe during 19892008: evidence of non-uniformity over time in rates of increase. Diabetologia 55:2142-2147

13. Harjutsalo V, Sund R, Knip M, Groop PH (2013) Incidence of type 1 diabetes in Finland. JAMA 310:427-428

14. Knip M, Simell O (2012) Environmental triggers of type 1 diabetes. Cold Spring Harb Perspect Med 7:a007690**This paper is a major source document for the current article

15. Oilinki T, Otonkoski T, Ilonen J, Knip M, Miettinen PJ (2012) Prevalence and characteristics of type 1 diabetes among Somali children and adolescents living in Helsinki, Finland. Pediatr Diabetes 13:176-180

16. Hermann R, Knip M, Veijola R et al (2003) Temporal changes in the frequencies of HLA genotypes in patients with type 1 diabetes: indication of an increased environmental pressure? Diabetologia 46:420-425

17. Gillespie KM, Bain SC, Barnett AH (2004) The rising incidence of childhood type 1 diabetes and reduced contribution of high-risk HLA haplotypes. Lancet 364:1645-1647

18. Pociot F, Akolkar B, Concannon P et al (2010) Genetics of type 1 diabetes: what's next? Diabetes 59:1561-1571

19. Pociot F, Lernmark $\AA$ (2016) Genetic risk factors for type 1 diabetes. Lancet 387:2331-2339

20. Pugliese A (2013) The multiple origins of type 1 diabetes. Diabet Med 30:135-146
21. Herold KC, Usmani-Brown S, Ghazi T et al (2015) $\beta$ cell death and dysfunction during type 1 diabetes development in at-risk individuals. J Clin Invest 125:1163-1174

22. Warram JH, Krolewski AS, Gottlieb MS, Kahn CR (1984) Differences in risk of insulin-dependent diabetes in offspring of diabetic mothers and diabetic fathers. N Engl J Med 311:149-152

23. Harjutsalo V, Reunanen A, Tuomilehto J (2006) Differential transmission of type 1 diabetes from diabetic fathers and mothers to their offspring. Diabetes 55:1517-1524

24. Luopajärvi K, Nieminen J, Ilonen J et al (2012) Expansion of $\mathrm{CD} 4+\mathrm{CD} 25+\mathrm{FoxP} 3+$ regulatory $\mathrm{T}$ cells in infants of mothers with type 1 diabetes. Pediatr Diabetes 13:400-407

25. Forrest JM, Menser MA, Burgess JA (1971) High frequency of diabetes mellitus in young adults with congenital rubella. Lancet 2:332-334

26. Forrest JM, Turnbull FM, Sholler GF et al (2002) Gregg's congenital rubella patients 60 years later. Med J Aust 177:664-667

27. Viskari H, Paronen J, Keskinen P et al (2003) Humoral beta-cell autoimmunity is rare in patients with the congenital rubella syndrome. Clin Exp Immunol 133:378-383

28. Dahlquist GG, Ivarsson S, Lindberg B, Forsgren M (1995) Maternal enteroviral infection during pregnancy as a risk factor for childhood IDDM. A population-based case-control study. Diabetes 44:408-413

29. Viskari H, Knip M, Tauriainen S et al (2012) Maternal enterovirus infection as a risk factor for type 1 diabetes in the exposed offspring. Diabetes Care 35:1328-1332

30. Mustonen N, Siljander H, Peet A et al (2017) Early childhood infections precede development of beta-cell autoimmunity and type 1 diabetes in children with HLA-conferred disease risk. Pediatr Diabetes. https://doi.org/10.1111/pedi.12547

31. Kallionpää H, Laajala E, Öling V et al (2014) The standard of hygiene and immune adaptation in newborn infants. Clin Immunol 155:136-147

32. Lamb MM, Myers MA, Barriga K, Zimmet PZ, Rewers M, Norris $\mathrm{JM}$ (2008) Maternal diet during pregnancy and islet autoimmunity in offspring. Pediatr Diabetes 9:135-141

33. Virtanen SM, Uusitalo L, Kenward MG et al (2011) Maternal food consumption during pregnancy and risk of advanced beta cell autoimmunity in the offspring. Pediatr Diabetes 12:95-99

34. Stene LC, Ulriksen J, Magnus P, Joner G (2000) Use of cod liver oil during pregnancy associated with lower risk of type 1 diabetes in the offspring. Diabetologia 43:1083-1092

35. Sørensen IM, Joner G, Jenum PA, Eskild A, Stene LC (2012) Serum long chain n-3 fatty acids (EPA and DHA) in the pregnant mother are independent of risk of type 1 diabetes in the offspring. Diabetes Metab Res Rev 28:431-438

36. Marjamäki L, Niinistö S, Kenward MG et al (2010) Maternal intake of vitamin D during pregnancy and risk of advanced beta cell autoimmunity and type 1 diabetes in offspring. Diabetologia 53:1599-1607

37. Sørensen IM, Joner G, Jenum PA, Eskild A, Torjesen PA, Stene LC (2012) Maternal serum levels of 25-hydroxy-vitamin D during pregnancy and risk of type 1 diabetes in the offspring. Diabetes 61: $175-178$

38. Miettinen ME, Reinert L, Kinnunen L et al (2012) Serum 25hydroxyvitamin $\mathrm{D}$ level during early pregnancy and type 1 diabetes risk in the offspring. Diabetologia 55:1291-1294

39. Cardwell CR, Stene LC, Joner G et al (2010) Birth weight and the risk of childhood-onset type 1 diabetes: a meta-analysis of observational studies using individual patient data. Diabetologia 53:641651

40. Rasmussen T, Stene LC, Samuelsen SO et al (2009) Maternal BMI before pregnancy, maternal weight gain during pregnancy, and risk of persistent positivity for multiple diabetes-associated 
autoantibodies in children with the high-risk HLA genotype: the MIDIA study. Diabetes Care 32:1904-1906

41. Arkkola T, Kautiainen S, Takkinen HM et al (2011) Relationship of maternal weight status and weight gain during pregnancy to the development of advanced beta cell autoimmunity in the offspring: a prospective birth cohort study. Pediatr Diabetes 12:478-484

42. Stene LV, Gale EAM (2013) The prenatal environment and type 1 diabetes. Diabetologia 56:1888-1897

43. Cardwell CR, Stene LC, Joner G et al (2010) Maternal age at birth and childhood type 1 diabetes: a pooled analysis of 30 observational studies. Diabetes 59:486-494

44. Virtanen SM, Kenward MG, Erkkola M et al (2006) Age at introduction of new foods and advanced beta-cell autoimmunity in young children with HLA-conferred susceptibility to type 1 diabetes. Diabetologia 49:1512-1521

45. Cardwell CR, Stene LC, Joner G et al (2011) Birth order and childhood type 1 diabetes risk: a pooled analysis of 31 observational studies. Int J Epidemiol 40:363-374

46. Cardwell CR, Stene LC, Joner G et al (2008) Caesarean section is associated with an increased risk of childhood onset type 1 diabetes: a meta-analysis of observational studies. Diabetologia 51: 726-735

47. Bonifacio E, Warncke K, Winkler C, Wallner M, Ziegler AG (2011) Cesarean section and interferon-induced helicase gene polymorphisms combine to increase childhood type 1 diabetesrisk. Diabetes 60:3300-3306

48. Yatsunenko T, Rey FE, Manary MJ et al (2012) Human gut microbiome viewed across age and geography. Nature 486:222 227

49. Yassour M, Vatanen T, Siljander H et al (2016) Natural history of the infant gut microbiome and impact of antibiotic treatments on bacterial strain diversity and stability. Sci Transl Med 8:343RA81

50. Knip M, Virtanen SM, Åkerblom HK (2010) Infant feeding and risk of type 1 diabetes. Am J Clin Nutr 91(Suppl):1506S-1513S

51. Virtanen SM, Knip M (2003) Nutritional risk predictors of $\beta$ cell autoimmunity and type 1 diabetes at a young age. Am J Clin Nutr 78:1053-1067

52. Norris JM, Barriga K, Klingensmith G et al (2003) Timing of initial cereal exposure in infancy and risk of islet autoimmunity. JAMA 290:1713-1720

53. Ziegler A-G, Schmid S, Huber D, Hummel M, Bonifacio E (2003) Early infant feeding and risk of developing type 1 diabetesassociated autoantibodies. JAMA 290:1721-1728

54. Kimpimäki T, Erkkola M, Korhonen S et al (2001) Short exclusive breast-feeding predisposes young children with increased genetic risk of type 1 diabetes to progressive beta-cell autoimmunity. Diabetologia 44:63-69

55. Holmberg H, Wahlberg J, Vaarala O, Ludvigsson J, the ABIS studygroup (2007) Short duration of breast-feeding as a risk factor for b-cell autoantibodies in 5-year-old children from the general population. Br J Nutr 97:111-116

56. Virtanen SM, Räsänne L, Aro A et al (1991) Infant feeding in Finnish children ,7 yr of age with newly diagnosed IDDM. Diabetes Care 14:415-417

57. Virtanen SM, Räsänen L, Ylönen K et al (1993) Early introduction of dairy products associated with increased risk of IDDM in Finnish children. Diabetes 42:1786-1790

58. Kostraba JN, Cruickshanks KJ, Lawler-Heavner J et al (1993) Early exposure to cow's milk and solid foods in infancy, genetic predisposition, and risk of IDDM. Diabetes 42:288-295

59. Wadsworth EJK, Shield JPH, Hunt LP, Baum J (1997) A casecontrol study of environmental factors associated with diabetes in the under 5s. Diabet Med 14:390-396

60. The EURODIAB Substudy 2 Study Group (2002) Rapid early growth is associated with increased risk of childhood type 1 diabetes in various European populations. Diabetes Care 25: $1755-1760$

61. Virtanen SM, Nevalainen J, Kronberg-Kippilä C et al (2012) Food consumption during childhood and advanced $\beta$-cell autoimmunity in young children with HLA-conferred susceptibility to type 1 diabetes: a nested case-control study. Am J Clin Nutr 95:471-478

62. Stene LC, Joner G, Norwegian Childhood Diabetes Study Group (2003) Use of cod liver oil during the first year of life is associated with lower risk of childhood-onset type 1 diabetes: a large, population-based, case-control study. Am J Clin Nutr 78:1128-1134

63. Norris JM, Yin X, Lamb MM et al (2007) Omega-3 polyunsaturated fatty acid intake and islet autoimmunity in children at increased risk for type 1 diabetes. JAMA 298:1420-1428

64. Niinistö S, Takkinen H-M, Erlund I et al (2017) Fatty acid status in infancy is associated with the risk of type 1 diabetes associated autoimmunity. Diabetologia 60:1233-1233

65. Knip M, Virtanen SM, Seppä K et al (2010) Dietary intervention in infancy and later signs of beta-cell autoimmunity. N Engl J Med 363:1900-1908

66. Knip M, Akerblom HK, Becker D et al (2014) Hydrolyzed infant formula and early $\beta$-cell autoimmunity — a randomized clinical trial. JAMA 311:2279-2287

67. Hummel S, Pflüger M, Hummel M, Bonifacio E, Ziegler AG (2011) Primary dietary intervention study to reduce the risk of islet autoimmunity in children at increased risk for type 1 diabetes: the BABYDIETstudy. Diabetes Care 34:1301-1305

68. Chase HP, Lescheck R, Rafkin-Mervis L et al (2009) Nutritional intervention to prevent (NIP) type 1 diabetes: a pilot trial. Infant Child Adolesc Nutr 1:99-107

69. Ziegler A-G, Hummel M, Schenker M, Bonifacio E (1999) Autoantibody appearance and risk for development of childhood diabetes in offspring of parents with type 1 diabetes: the 2-year analysis of the German BABYDIAB study. Diabetes 48:460-468

70. Sabbah E, Savola K, Ebeling T et al (2000) Genetic, autoimmune, and clinical characteristics of childhood- and adult-onset type 1 diabetes mellitus. Diabetes Care 23:1326-1332

71. Vaarala O, Knip M, Paronen J et al (1999) Cow milk formula feeding induces primary immunization to insulin in infants at genetic risk for type 1 diabetes. Diabetes 48:1389-1394

72. Vaarala O, Ilonen J, Ruohtula $\mathrm{T}$ et al (2012) Removal of bovine insulin from cow's milk formula and early initiation of beta-cell autoimmunity. Arch Pediatr Adolesc Med 166:608-614

73. Hummel M, Bonifacio E, Naserke HE, Ziegler AG (2002) Elimination of dietary gluten does not reduce titers of type 1 diabetes-associated autoantibodies in high-risk subjects. Diabetes Care 25:1111-1116

74. Pastore MR, Bazzigaluppi E, Belloni C, Arcovio C, Bonifacio E, Bosi E (2003) Six months of gluten-free diet do not influence autoantibody titers, but improve insulin secretion in subjects at high risk for type 1 diabetes. J Clin Endocrinol Metab 88:162-165

75. The EURODIAB Substudy 2 Study Group (1999) Vitamin D supplement in early childhood and risk of type I (insulindependent) diabetes mellitus. Diabetologia 42:51-54

76. Hyppönen E, Läärä E, Järvelin MR, Virtanen SM (2001) Intake of vitamin D and risk of type 1 diabetes: a birth cohort study. Lancet 358:1500-1504

77. Mäkinen M, Mykkänen JP, Koskinen MK et al (2016) Serum 25hydroxyvitamin D concentrations in children with genetic type 1 diabetes susceptibility progressing to autoimmunity and clinical disease. J Clin Endocrinol Metab 101:723-729

78. Uusitalo U, Liu X, Yang J et al (2016) Association of early exposure of probiotics and islet autoimmunity in the TEDDY study. JAMA Pediatr 170:20-28

79. Eizirik DL, Miani M, Cardozo AK (2013) Signalling danger: endoplasmic reticulum stress and the unfolded protein response in pancreatic islet inflammation. Diabetologia 56:234-241 
80. Hyppönen E, Kenward MG, Virtanen SM et al (1999) Infant feeding, early weight gain and risk of type 1 diabetes. Diabetes Care 22:1961-1965

81. Hyppönen E, Virtanen SM, Kenward MG, Knip M, Åkerblom HK, the Childhood Diabetes in Finland Study Group (2000) Obesity, increased linear growth and risk of type 1 diabetes mellitus in children. Diabetes Care 23:1755-1760

82. Lamb MM, Yin X, Zerbe GO et al (2009) Height growth velocity, islet autoimmunity and type 1 diabetes development: the diabetes autoimmunity study in the young. Diabetologia 52:2064-2071

83. Rasmussen T, Witso E, Tapia G, Stene LC, Ronningen KS (2011) Selfreported lower respiratory tract infections and development of islet autoimmunity in children with the type 1 diabetes high-risk HLA genotype: the MIDIA study. Diabetes Metab Res Rev 27: 834-837

84. Beyerlein A, Wehweck F, Ziegler AG, Pflueger M (2013) Respiratory infections in early life and the development of islet autoimmunity in children at increased type 1 diabetes risk: evidence from the BABYDIET study. JAMA Pediatr 167:800-807

85. Beyerlein A, Donnachie E, Jergens S, Ziegler AG (2016) Infections in early life and development of type 1 diabetes. JAMA 315:1899-1901

86. Lönnrot M, Korpela K, Knip M et al (2000) Enterovirus infection as a risk factor for $\beta$-cell autoimmunity in a prospectively observed birth cohort - the Finnish Diabetes Prediction and Prevention (DIPP) Study. Diabetes 49:1314-1318

87. Oikarinen S, Martiskainen M, Tauriainen S et al (2011) EnterovirusRNA in blood is linked to the development of type 1 diabetes. Diabetes 60:276-279

88. Kimpimäki T, Kupila A, Hämäläinen A-M et al (2001) The first signs of $\beta$-cell autoimmunity appear in infancy in genetically susceptible children from the general population: the Finnish type 1 diabetes prediction and prevention study. J Clin Endocrinol Metab $86: 4782-4788$

89. Laitinen $\mathrm{OH}$, Honkanen $\mathrm{H}$, Tolonen O et al (2014) Coxsackievirus B1 induces beta-cell autoimmunity that portends type 1 diabetes. Diabetes 63:446-455

90. Fuchtenbusch M, Irnstetter A, Jager G, Ziegler AG (2001) No evidence for an association of coxsackie virus infections during pregnancy and early childhood with development of islet autoantibodies in offspring of mothers or fathers with type 1 diabetes. J Autoimmun 17:333-340

91. Graves PM, Rotbart HA, Nix WA et al (2003) Prospective study of enteroviral infections and development of $\beta$-cell autoimmunity. Diabetes autoimmunity study in the young (DAISY). Diabetes Res Clin Pract 59:51-61

92. Stene LC, Oikarinen S, Hyöty H et al (2010) Enterovirus infection and progression from islet autoimmunity to type 1 diabetes: the diabetes and autoimmunity study in the young (DAISY). Diabetes 59:3174-3180

93. Simonen-Tikka ML, Pflueger M, Klemola P et al (2011) Human enterovirus infections in children at increased risk for type 1 diabetes: the Babydiet study. Diabetologia 54:2995-3002

94. Honkanen H, Oikarinen S, Nurminen N et al (2017) Detection of enteroviruses in stools precedes the appearance of islet autoimmunity with a delay of several months - possible evidence for slowly operating mechanisms in virus-induced autoimmunity. Diabetologia 60:424-431

95. Hyöty H, Knip M (2014) Developing a vaccine for type 1 diabetes through targeting enteroviral infections. Expert Rev Vaccines 13: 989-999

96. Knip M, Hyöty H (2008) Environmental determinants: the role of viruses and standard of hygiene. In: Dabelea D, Klingensmith GJ (eds) Epidemiology of pediatric and adolescent diabetes. Informa Healthcare, New York, pp 63-74
97. Honeyman MC, Stone NL, Harrison LC (1998) T-cell epitopes in type 1 diabetes autoantigen tyrosine phosphatase IA-2: potential for mimicry with rotavirus and other environmental agents. Mol Med 4:231-239

98. Honeyman MC, Stone NL, Falk BA, Nepom G, Harrison LC (2010) Evidence for molecular mimicry between human T cell epitopes in rotavirus and pancreatic islet autoantigens. J Immunol 184:2204-2210

99. Honeyman MC, Coulson BS, Stone NL et al (1999) Association between rotavirus infection and pancreatic islet autoimmunity in children at risk of developing type 1 diabetes. Diabetes 49:1319 1324

100. Blomquist M, Juhela S, Erkkilä S et al (2002) Rotavirus infections and development of diabetes-associated autoantibodies during the first 2 years of life. Clin Exp Immunol 128:511-515

101. Aagaard K, Ma J, Antony KM et al (2014) The placenta harbors a unique microbiome. Sci Transl Med 6:237ra65

102. Knip M, Siljander H (2016) The role of the intestinal microbiota in type 1 diabetes mellitus. Nat Rev Endocrinol 12:154-167

103. Matamoro S, Gras-Leguen C, Le Vacon F, Potel G, de La Cochetiere MF (2013) Development of intestinal microbiota in infants and its impact on health. Trends Microbiol 21:167-173

104. Mackie RI, Sghir A, Gaskins HR (1999) Developmental microbial ecology of the neonatal gastrointestinal tract. Am J Clin Nutr 69: S1035-S1045

105. Dominguez-Bello MG, Blaser MJ, Ley RE, Knight R (2011) Development of the human gastrointestinal microbiota and insights from high-throughput sequencing. Gastroenterology 140: 1713-1719

106. Dominguez-Bello MG, Costello EK, Contreras M et al (2010) Delivery mode shapes the acquisition and structure of the initial microbiota across multiple body habitats in newborns. Proc Natl Acad Sci U S A 107:11971-11975

107. Biasucci G, Benenati B, Morelli L, Bessi E, Boehm G (2008) Cesarean delivery may affect the early biodiversity of intestinal bacteria. J Nutr 138:1796S-1800S

108. Jakobsson HE, Abrahamsson TR, Jenmalm MC et al (2014) Decreased gut microbiota diversity, delayed Bacteroidetes colonization and reduced Th1 responses in infants delivered by caesarean section. Gut 63:559-566

109. Giongo A, Mukherjee N, Gano KA et al (2011) Toward defining the autoimmune microbiome for type 1 diabetes. ISME J 5:82-91

110. Brown CT, Davis-Richardson AG, Giongo A et al (2011) Gut microbiome metagenomics analysis suggests a functional model for the development of autoimmunity for type 1 diabetes. PLoS One 6:e25792

111. Kostic AD, Gevers D, Siljander $H$ et al (2015) The dynamics of the human infant gut microbiome in development and in progression toward type 1 diabetes. Cell Host Microbe 17:260-273

112. Vatanen T, Kostic AD, d'Hennezel E et al (2016) Variation in microbiome LPS immunogenicity contributes to autoimmunity in humans. Cell 165:842-853

113. Kondrashova A, Reunanen A, Romanov A et al (2005) A sixfold gradient in the incidence of type 1 diabetes at the eastern border of Finland. Ann Med 37:67-72

114. Kondrashova A, Seiskari T, Ilonen J, Knip M, Hyöty H (2013) The "hygiene hypothesis" and the sharp gradient in the incidence of autoimmune and allergic diseases between Russian Karelia and Finland. APMIS 121:478-493

115. Davis-Richardson A, Ardissone A, Dias R et al (2014) Bacteroides dorei dominates gut microbiome prior to autoimmunity in Finnish children at high risk for type 1 diabetes. Front Microbiol 5:678

116. Mikkelsen KH, Knop FK, Vilsbøll T, Frost M, Hallas J, Pottegård A (2017) Use of antibiotics in childhood and risk of Type 1 
diabetes: a population-based case-control study. Diabet Med 34: 272-277

117. Clausen TD, Bergholt T, Bouaziz O (2016) Broad-spectrum antibiotic treatment and subsequent childhood type 1 diabetes: a nationwide Danish cohort study. PLoS One 11:e0161654

118. Moulder R, Lahesmaa R (2016) Early signs of disease in type 1 diabetes. Pediatr Diabetes 17(Suppl S22):43-48

119. Roadmap Epigenomics Consortium, Kundaje A, Meuleman W et al (2015) Integrative analysis of 111 reference human epigenomes. Nature 518:317-330

120. Orban T, Kis J, Szereday L et al (2007) Reduced CD4+ T-cellspecific gene expression in human type 1 diabetes mellitus. $\mathrm{J}$ Autoimmun 28:177-187

121. Figueroa-Colon R, Arani RB, Goran MI, Weinsier RL (2000) Paternal body fat is a longitudinal predictor of changes in body fat in premenarcheal girls. Am J Clin Nutr 71:829-834

122. Penesova A, Bunt JC, Bogardus C, Krakoff J (2010) Effect of paternal diabetes on pre-diabetic phenotypes in adult offspring. Diabetes Care 33:1823-1828

123. Wei Y-PPY, Yang C-RR, Zhao Z-A et al (2014) Paternally induced transgenerational inheritance of susceptibility to diabetes in mammals. Proc Natl Acad Sci U S A 111:1873-1878

124. Zhang Y, Collier F, Naselli G et al (2016) Cord blood monocytederived inflammatory cytokines suppress IL-2 and induce nonclassic "TH 2-type" immunity associated with development of food allergy. Sci Transl Med 8:321ra8

125. Jin Y, Sharma A, Bai S et al (2014) Risk of type 1 diabetes progression in islet autoantibody-positive children can be further stratified using expression patterns of multiple genes implicated in peripheral blood lymphocyte activation and function. Diabetes 63:2506-2515

126. Elo LL, Mykkanen J, Nikula T et al (2010) Early suppression of immune response pathways characterizes children with prediabetes in genome-wide gene expression profiling. J Autoimmun 35: 70-76

127. Kallionpää H, Elo LL, Laajala E et al (2014) Innate immune activity is detected prior to seroconversion in children with HLAconferred T1D susceptibility. Diabetes 63:2402-2414
128. Ferreira RC, Guo H, Coulson RM et al (2014) A type I interferon transcriptional signature precedes autoimmunity in children genetically at risk for type 1 diabetes. Diabetes 63:2538-2550

129. Oresic M, Simell S, Sysi-Aho M et al (2008) Dysregulation of lipid and amino acid metabolism precedes islet autoimmunity in children who later progress to type1 diabetes. J Exp Med 205: 2975-2984

130. Oresic M, Gopalacharyulu P, Mykkanen J et al (2013) Cord serum lipidome in prediction of islet autoimmunity and type 1 diabetes. Diabetes 62:3268-3274

131. La Torre D, Seppanen-Laakso T, Larsson HE et al (2013) Decreased cord-blood phospholipids in young age-at onset type 1 diabetes. Diabetes 62:3951-3956

132. Metz TO, Qian WJ, Jacobs JM et al (2008) Application of proteomics in the discovery of candidate protein biomarkers in a diabetes autoantibody standardization program sample subset. J Proteome Res 7:698-707

133. Zhi W, Sharma A, Purohit S et al (2011) Discovery and validation of serum protein changes in type 1 diabetes patients using high throughput two dimensional liquid chromatography-mass spectrometry and immunoassays. Mol Cell Proteomics 10: M111.012203

134. Zhang Q, Fillmore TL, Schepmoes AA et al (2013) Serum proteomics reveals systemic dysregulation of innate immunity in type 1 diabetes. J Exp Med 210:191-203

135. Moulder R, Bhosale SD, Erkkila T et al (2015) Serum proteomes distinguish children developing type 1diabetes in a cohort with HLA-conferred susceptibility. Diabetes 64:2265-2278

136. Parikka V, Näntö-Salonen K, Saarinen M et al (2012) Early seroconversion and rapidly increasing autoantibody concentrations predict prepubertal manifestation of type 1 diabetes in children at genetic risk. Diabetologia 55:1926-1936

137. Phillips JE, Couper JJ, Penno MA, Harrison LC, ENDIA Study Group (2016) Type 1 diabetes: a disease of developmental origins. Pediatr Diabetes 18:417-421 